\title{
IMPACTO AMBIENTAL EM ASSENTAMENTOS DA REFORMA AGRÁRIA NO MATO GROSSO
}

\author{
Marco Antonio Vieira Morais ${ }^{1}$, Roberto Antonio Ticle de Melo Sousa ${ }^{2}$, Reginaldo Brito daCosta ${ }^{3}$, \\ Alberto Dorval $^{3}$, Romano Timofeiczyk Júnior ${ }^{4}$ \\ ${ }^{1}$ Tecnólogo em Gestão Ambiental, M.Sc.,IFMT, Cuiabá, MT, Brasil -ecogestor@hotmail.com \\ ${ }^{2}$ Eng. Florestal, Economista, Dr., PPGCFA/FENF/UFMT, Cuiabá, MT, Brasil -rmts@ terra.com.br \\ ${ }^{3}$ Eng. Florestal, Dr., PPGCFA/FENF/UFMT, Cuiabá, MT, Brasil - reg.brito.costa@gmail.com;adorval@ufmt.br \\ ${ }^{4}$ Eng. Florestal, Dr., Depto. de Economia Rural e Extensão, UFPR, Curitiba, PR, Brasil -romano@ufpr.br \\ Recebido para publicação: 20/10/2010 - Aceito para publicação: 09/04/2012
}

\begin{abstract}
Resumo
A pesquisa objetivou avaliar o impacto ambiental de propriedades rurais de assentamentos da reforma agrária. Utilizou-se o Sistema APOIA Novo Rural em sete propriedades de dois assentamentos rurais: Santo Antônio da Fartura e Xavante, sendo três propriedades no município de Campo Verde e quatro no município de Confresa. Conclui-se que as atividades produtivas desenvolvidas nas propriedades avaliadas não comprometem a qualidade ambiental; a dimensão gestão e administração apresentou pior desempenho ambiental; o indicador fósforo apresenta limitações logísticas para sua aplicação; uma única linha de referência limita a interpretação do impacto ambiental.

Palavras-chave: Agricultura familiar; avaliação ambiental; Embrapa.
\end{abstract}

\begin{abstract}
Environmental impact on agrarian reform settlements in Mato Grosso. This research aimed to evaluate environmental impact of rural properties as result of agrarian reform settlements. It used the system APOIA Novo Rural in seven properties of two rural settlements: Santo Antônio da Fartura and Xavante, three of such properties are in the municipality of Campo Verde and four in the municipality of Confresa. It has as conclusion that: the productive activities developed in the evaluated properties do not compromise environmental quality; management and administration presented the worst environmental performance; the phosphorus indicator presents logistical limitations to its application; a single line of reference limits interpretation of environmental impact.

Keywords: Family farming; environmental evaluation; Embrapa.
\end{abstract}

\section{INTRODUÇÃO}

Um grande número de projetos de assentamentos da reforma agrária não prosperam, isto é, não conseguem desenvolver a sustentabilidade da produção. Outrossim, os projetos de assentamentos da reforma agrária estão relacionados com o aumento do desmatamento na Amazônia e têm sido objeto de interesse de instâncias governamentais e civis, que exigem o repensar do atual modelo de assentamento, no sentido de viabilizar assentamentos ambientalmente sustentáveis (GUERRA, 2006).

Portanto, a necessidade de avaliar e acompanhar esses assentamentos, bem como a implantação de novos, é essencial para o desenvolvimento rural sustentável. O instrumento reconhecido para esse acompanhamento é a avaliação de impacto ambiental.

Pode-se considerar que o procedimento de avaliação de impacto ambiental não se limita à implementação de políticas públicas (licenciamentos ambientais), sendo também instrumentos de auxílio à tomada de decisão dos produtores rurais quanto às melhores opções relacionadas às práticas produtivas (RODRIGUES et al., 2003). As avaliações de impacto ambiental podem ainda ser utilizadas para certificação ambiental (RODRIGUES et al., 2006).

As definições de diferentes autores se completam, ao definirem que a avaliação de impacto ambiental é um procedimento sistemático, técnico, administrativo e político, que deve apresentar a interação entre a fonte de impacto e o meio receptor, contemplando o meio físico, biológico e 
socioeconômico, para permitir a identificação, predição, prevenção, mitigação, análise, comunicação de impactos ambientais e interpretação quantitativa e qualitativa das alterações no meio ambiente (BRAGA, et al., 2002; SANTOS, 2004; RODRIGUES; RODRIGUES, 2006).

Dos conceitos encontrados na literatura, a concordância é que impacto ambiental se refere a uma determinada alteração de um parâmetro ambiental (ALMEIDA; SOARES, 2008; SÁNCHEZ, 2006; SANTOS, 2004; PEREIRA, et al., 2001).

O Sistema APOIA, criado devido à carência de uma metodologia adequada para avaliar o impacto ambiental no contexto de um cenário em que as atividades agrícolas tradicionais, o agroturismo e outras atividades são realizadas (RODRIGUES; CAMPANHOLA, 2003),foi desenvolvido pelos pesquisadores Dr. Geraldo Stachetti Rodrigues e Dr. Clayton Campanhola, da Empresa Brasileira de Pesquisa Agropecuária (EMBRAPA) - Meio Ambiente, publicado em 2003 (RODRIGUES; CAMPANHOLA, 2003). agrária.

Objetivou-se avaliar o impacto ambiental de propriedades rurais de assentamentos da reforma

\section{MATERIAL E MÉTODOS}

O software Sistema APOIA-Novo Rural foi aplicado em dois assentamentos rurais: Santo Antônio da Fartura e Xavante, o primeiro localizado na margem esquerda da rodovia BR 070, no sentido Cuiabá-Campo Verde, tendo suas terras nos municípios de Santo Antonio do Leverger (longitude $-56^{\circ} 04^{\prime}$ W e latitude $15^{\circ} 51^{\prime}$ S) e Campo Verde (longitude $-55^{\circ} 09^{\prime}$ W e latitude $-15^{\circ} 31^{\prime}$ S), e o segundo localizado às margens da BR 158, no município de Confresa (longitude $-51^{\circ} 31^{\prime} \mathrm{W}$ e latitude $-10^{\circ} 36^{\prime} \mathrm{S}$ ), ambos no estado do Mato Grosso.

Foram selecionadas sete propriedades para aplicação do software, sendo três no município de Campo Verde e quatro no município de Confresa. A seleção das propriedades foi baseada em questões de logística referentes às condições e disponibilidade de recursos financeiros da pesquisa.

A tabela 1contém a descrição das propriedades avaliadas com o Sistema APOIA-Novo Rural.

Tabela 1. Descrição das propriedades avaliadas com o Sistema APOIA-Novo Rural.

Table 1. Description of the assessed properties with the System APOIA-Novo Rural.

\begin{tabular}{|c|c|c|c|c|}
\hline Cod & $\begin{array}{l}\text { Atividade } \\
\text { produtiva }\end{array}$ & $\begin{array}{c}\text { Área } \\
\text { (ha) }\end{array}$ & Município & Principais dificuldades de implantação da atividade \\
\hline P1 & $\begin{array}{l}\text { Silvicultura - } \\
\text { eucalipto }\end{array}$ & 15 & $\begin{array}{l}\text { Campo } \\
\text { Verde }\end{array}$ & $\begin{array}{l}\text { (1) Deslocamento para os centros urbanos; } \\
\text { (2) Acesso aos financiamentos; } \\
\text { (3) Acesso à assistência técnica. }\end{array}$ \\
\hline $\mathrm{P} 2$ & $\begin{array}{l}\text { Horticultura } \\
\text { convencional }\end{array}$ & 30 & $\begin{array}{l}\text { Campo } \\
\text { Verde }\end{array}$ & $\begin{array}{l}\text { (1) Ação de atravessadores; } \\
\text { (2) Acesso à assistência técnica; } \\
\text { (3) Distância do centro consumidor. }\end{array}$ \\
\hline P3 & $\begin{array}{l}\text { Horticultura } \\
\text { convencional }\end{array}$ & 23 & $\begin{array}{l}\text { Campo } \\
\text { Verde }\end{array}$ & $\begin{array}{l}\text { (1) Deslocamentos para os centros urbanos; } \\
\text { (2) Acesso aos financiamentos; } \\
\text { (3) Acesso à assistência técnica. }\end{array}$ \\
\hline P4 & $\begin{array}{l}\text { Avicultura de } \\
\text { corte e postura }\end{array}$ & 24 & Confresa & $\begin{array}{l}\text { (1) Acesso aos financiamentos; } \\
\text { (2) Dificuldade de estocagem de grãos; } \\
\text { (3) Licenciamento ambiental e sanitário. }\end{array}$ \\
\hline P5 & $\begin{array}{l}\text { Horticultura } \\
\text { convencional e } \\
\text { culturas anuais }\end{array}$ & 52 & Confresa & $\begin{array}{l}\text { (1) Acesso à assistência técnica; } \\
\text { (2) Qualidade das sementes comercializadas no mercado local; } \\
\text { (3) Acesso aos financiamentos. }\end{array}$ \\
\hline P5 & $\begin{array}{l}\text { Horticultura } \\
\text { convencional e } \\
\text { pecuária leiteira }\end{array}$ & 43 & Confresa & (1) Acesso à assistência técnica. \\
\hline P7 & $\begin{array}{l}\text { Horticultura } \\
\text { convencional }\end{array}$ & 50 & Confresa & $\begin{array}{l}\text { (1) Elevado custo de preparo do solo; } \\
\text { (2) Acesso à assistência técnica; } \\
\text { (3) Preços praticados no comércio local. }\end{array}$ \\
\hline
\end{tabular}

As propriedades denominadas P1, P2 e P3 localizam-se no Projeto de Assentamento Santo Antônio da Fartura, no município de Campo Verde, e as denominadas P4, P5, P6 e P7 encontram-se estabelecidas no Projeto de Assentamento Xavante, no município de Confresa, estado de Mato Grosso. 
A atividade produtiva considerada na avaliação refere-se à principal ocupação implantada na propriedade com fins comerciais, porém existem em algumas propriedades outras atividades que não são destinadas à comercialização.

O Sistema APOIA-Novo Rural consiste de matrizes ponderadas construídas no MS-Excel®, que utilizam indicadores de desempenho ambiental para proceder à avaliação ambiental. Os indicadores são distribuídos nas cinco dimensões ambientais a seguir: I) Ecologia da paisagem; II) Qualidade dos compartimentos ambientais; III) Valores sócio culturais; IV) Valores econômicos; V) Gestão e administração(RODRIGUES et al., 2003).

Os 62 indicadores foram formulados considerando-se os diferentes métodos de avaliação de impactos ambientais descritos na literatura, com contribuições de discussões em grupos, workshops e consultas a especialistas. Esses indicadores foram selecionados, compostos e organizados de forma a contemplar uma ampla gama de efeitos ambientais aplicáveis em quaisquer atividades rurais (RODRIGUES et al., 2003).

Cada um dos 62 indicadores dá origem a um índice, calculado em uma matriz específica para cada um dos indicadores, o que é convertido automaticamente por funções de correspondência em valor de utilidade, numa escala que varia entre 0 (zero, a pior situação) e 1 (um, a melhor situação).

Adotou-se a expressão índice de impacto ambiental do indicador (IIAI)para se referir ao valor de utilidade, possuindo, portanto, o mesmo valor numérico.

A média dos índices de impacto ambiental dos indicadores, que compõem qualquer uma das dimensões ambientais utilizadas, dá origem ao índice de impacto ambiental da referida dimensão.

O índice final da avaliação calculado pelo software é denominado índice de impacto ambiental da propriedade (IIAP), sendo obtido através da média do valor de utilidade dos 62 indicadores.

A escala espacial estabelecida para a aplicação do software é a propriedade rural. Portanto, o limite da avaliação corresponde aos limites físicos da propriedade avaliada. A escala temporal é estabelecida pela situação anterior ao início da principal atividade da propriedade e pela situação presente.

O padrão ambiental pré-definido como linha-base para avaliação será de 0,70 , um valor padrão que permite a comparação dos resultados obtidos na avaliação da propriedade e que indicará se a atividade produtiva desenvolvida na propriedade não alterou o meio ambiente local. Essa é a situação minimamente esperada pelo estabelecimento rural.

Os produtos finais apresentados pelo uso do software serão o IIAP, cinco índices de impacto ambiental das dimensões (IIAD) e 62 IIAI, sendo um para cada indicador. Esses três resultados serão apresentados de duas formas: por meio de índices e gráficos na própria interface do software e no relatório de avaliação de impacto ambiental do Sistema APOIA-Novo Rural.

Não é objetivo desse software estabelecer um ranking entre as propriedades, pois não existe comparação entre as propriedades analisadas, logo, não se pode afirmar que uma propriedade que possua índice 0,80 de impacto ambiental da propriedade seja ambientalmente melhor ou mais correta em suas práticas produtivas que outra com índice de impacto ambiental da propriedade de 0,75 . Essa afirmação baseia-se no fato de que cada avaliação refere-se a um estabelecimento particularizado dentro de um contexto específico, em que os indicadores realizam uma comparação entre dois momentos distintos (o antes e o depois do início da atividade produtiva em avaliação) da mesma propriedade.

A análise dos índices de impacto ambiental é feita na ordem inversa da obtenção do índice de impacto ambiental da propriedade. O primeiro nível é o da propriedade como IIAP que representa de forma objetiva o impacto ambiental da propriedade conseguido com a média dos índices de impacto das dimensões.

O segundo nível é o IIAD, que representa o impacto da atividade desenvolvida em uma determinada dimensão específica, obtido pela média dos IIAI que compõem a respectiva dimensão em avaliação.

O terceiro nível é o IIAI, obtido a partir da matriz ponderada.

A coleta de dados foi realizada no mês de junho de 2009 nas propriedades do Assentamento Santo Antonio da Fartura e em julho de 2009 para as propriedades do Assentamento Xavante, por meio de visitas técnicas às propriedades selecionadas, para coleta de amostras de solo e água. Outros dados foram obtidos por meio de entrevista estruturada junto ao(s) proprietário(s), segundo os indicadores do Sistema APOIA, e posterior verificação in loco para validação das informações prestadas. Como 
protocolo para aplicação do Sistema APOIA-Novo Rural, adotaram-se os subsídios de Rodrigues e Moreira (2007).

Coletas de amostras de água e solo foram feitas conforme as recomendações de Filizola et al. (2006), para os indicadores que exigem análises laboratoriais e que compõem a dimensão compartimentos ambientais, subdivisão água superficial, água subterrânea e solo. A análise das amostras de água superficial e água subterrânea seguiu as indicações da American Public Health Association (1985), e a análise de solos obedeceu ao que Claessen et al. (1997) recomendam.

\section{RESULTADOS E DISCUSSÃO}

Na figura 1estão representados os valores dos índices de impacto ambiental das propriedades em que aplicou-se o software.
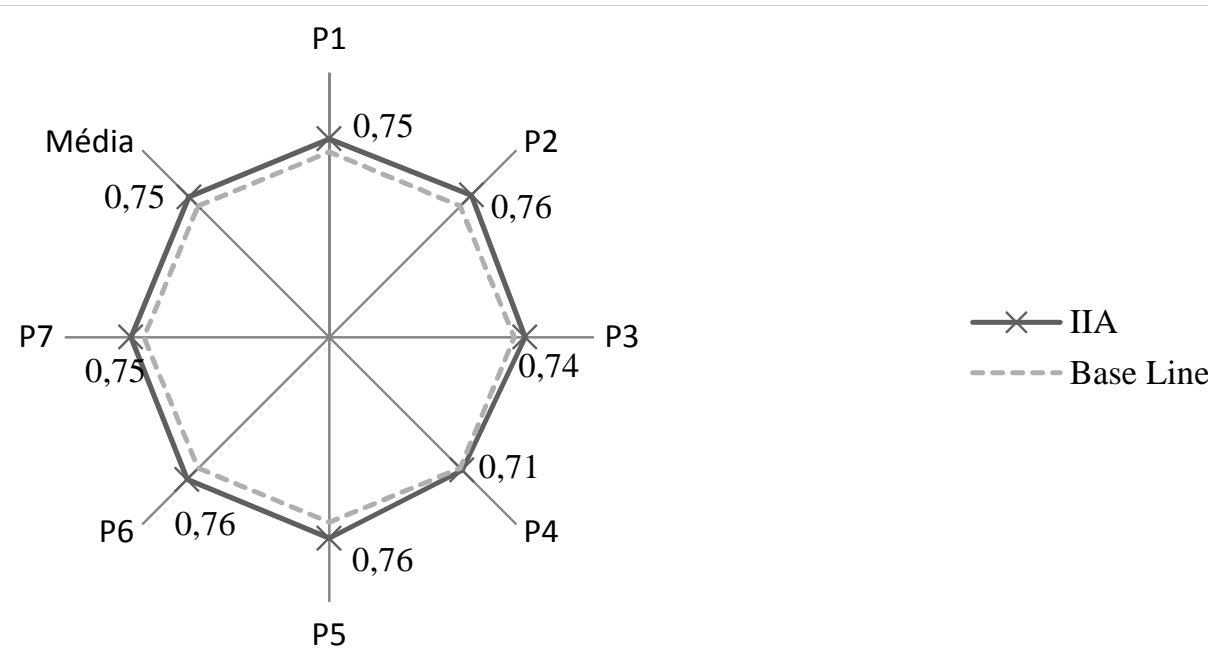

Figura1. Índices de impacto ambiental das propriedades avaliadas.

Figure 1. Indexes of environmental impact for the evaluated properties.

A representação do impacto ambiental conforme o descrito na figuralfacilitaao produtor a compreensão da amplitude de sua ação produtiva, corroborando as afirmações de Rodrigues e Campanhola (2003).

Para as atividades analisadas, os índices de impacto ambiental das propriedades variaram entre 0,71 e 0,76, com uma amplitude de 0,05. Ramos Filho et al. (2004), pesquisando estabelecimentos rurais dedicados ao agroturismo, verificaram a existência de uma variação entre 0,65 e 0,76, com uma amplitude de 0,11 , considerada pequena pelos autores. Portanto, os resultados obtidos nesta pesquisa estão dentro do esperado para o conjunto das propriedades avaliadas.

O Sistema APOIA-Novo Rural, ao apresentar um índice agregado de impacto ambiental da propriedade, simplifica a perspectiva da situação ambiental da propriedade rural, constituindo-se numa vantagem para a análise objetiva. Essa constatação corrobora as conclusões de Rodrigues e Campanhola (2003),por mostrar que uma das principais vantagens do software do APOIA-Novo Rural é agregar componentes de diferentes naturezas e elaborar índices de impacto por dimensões (índices parciais de impacto ambiental) e índice de impacto ambiental da propriedade.

Neste trabalho contatou-se que, para o entendimento da significância do índice de impacto ambiental da propriedade, deve-se realizara análise do índice de impacto ambiental por dimensão, identificando quais dimensões possuem desempenho ambiental abaixo da linha-base $(0,70)$,e estabelecer um ranking entre as dimensões. Posteriormente, a análise deve ser realizada nas dimensões, caso a caso, observando-se os indicadores que interferem negativamente no índice de impacto ambiental da dimensão em questão. 
Na tabela 2 são observados os valores dos índices de impacto ambiental das dimensões para cada uma das propriedades avaliadas.

Entre as atividades analisadas, a propriedade dedicada à avicultura de corte e postura (P4) foi a que apresentou o pior índice de impacto ambiental da dimensão ecologia da paisagem $(0,62)$; o melhor desempenho foi verificado na propriedade dedicada à horticultura convencional (P7), 0,81. Ambas as propriedades estão localizadas no Assentamento Xavante, município de Confresa/MT.

Os indicadores que fizeram com que houvesse uma diferença de 0,19 entre P4 (avicultura de corte e postura) e P7 (horticultura convencional) para IIAD ecologia da paisagem foram: cumprimento com requerimento de reserva legal, cumprimento com requerimento de áreas de preservação permanente e diversidade da paisagem (Tabela 4). Pode-se inferir que a não observância das determinações legais afetou negativamente o desempenho ambiental nessa dimensão.

Tabela 2. Valores dos índices de impacto ambiental por dimensões ambientais para sete propriedades avaliadas.

Table 2. Values of indexes of environmental impact by environmental dimensions for seven assessed properties.

\begin{tabular}{lcccccccc}
\hline Dimensões ambientais & P1 & P2 & P3 & P4 & P5 & P6 & P7 & Média \\
\hline Ecologia da paisagem & 0,67 & 0,72 & 0,75 & 0,62 & 0,67 & 0,72 & 0,81 & 0,71 \\
Compartimentos ambientais & 0,86 & 0,84 & 0,82 & 0,79 & 0,84 & 0,78 & 0,81 & 0,82 \\
Valores socioculturais & 0,70 & 0,65 & 0,69 & 0,64 & 0,68 & 0,75 & 0,64 & 0,68 \\
Valores econômicos & 0,72 & 0,79 & 0,72 & 0,83 & 0,85 & 0,81 & 0,72 & 0,78 \\
Gestão e administração & 0,42 & 0,45 & 0,37 & 0,60 & 0,53 & 0,65 & 0,49 & 0,50 \\
\hline
\end{tabular}

As duas propriedades dedicadas à horticultura convencional (P2 e P3) do Assentamento Santo Antonio da Fartura, em Campo Verde/MT, obtiveram índices 0,72 e 0,75, respectivamente, para o impacto ambiental na ecologia da paisagem. Essa diferença não é significativa e evidencia o bom desempenho ambiental das duas propriedades.

A propriedade que desenvolve a silvicultura de eucalipto $(\mathrm{P} 1)$ e a que se dedica à horticultura convencional e culturas anuais (P5) apresentaram índice de impacto ambiental de 0,67 para a dimensão ecologia da paisagem, o que está próximo da linha-base, que é de 0,70. Aproxima-se, portanto, da situação mínima desejada com relação à ecologia da paisagem. Isso implica que as atividades acima mencionadas (P1 e P5) causaram pouca alteração na paisagem. Para essa dimensão, tais atividades são consideradas de baixo impacto ambiental.

A média do índice de impacto ambiental da dimensão ecologia da paisagem nas propriedades avaliadas é de 0,71,índice acima do mínimo desejado para que a dimensão seja considerada ambientalmente estável. Esse dado permite inferir que as atividades desenvolvidas nas propriedades de assentamento não causam impacto significativo nessa dimensão.

Os índices de impacto ambiental dos indicadores que compõem a dimensão ecologia da paisagem para cada propriedade avaliada encontram-se na tabela 3.

Os proprietários da P4 e P5 justificaram o valor observado inferior a 0,70 (linha-base) no índice de impacto ambiental do indicador requisito de reserva legal. Eles alegaram que, no período que chegaram à região, o governo incentivava a derrubada e que a área ocupada era anteriormente um latifúndio, com a maioria de sua extensão recoberta por pastagem plantada.

Embora a área de reserva legal não esteja averbada, pois não há escrituração do imóvel, os proprietários informaram que aquela área é a destinada ao cumprimento da legislação que estabelece a área mínima de reserva legal.

Identificou-se que P1, P2 e P3 possuem a reserva legal na forma de condomínio (uma única reserva legal para todos ou para grupo de lotes). Nesse sentido, a aplicação direta do indicador requerimento de reserva legal torna-se parcialmente inviável, pois as responsabilidades pelo cumprimento do requisito não se restringem a um indivíduo e sim a um grupo, embora a opção por esse tipo de reserva legal receba críticas positivas do ponto de vista ecológico. Sendo os proprietários elementos de um grupo de interesse, eles podem influenciar na conservação/preservação da reserva legal, mesmo sob a forma de condomínio. Portanto, continua havendo a pertinência e aplicabilidade do indicador cumprimento com requerimento de reserva legal. 
Tabela 3. Índices de impacto ambiental dos indicadores da dimensão ecologia da paisagem para as propriedades estudadas.

Table 3. Indexes of environmental impact of indicators of landscape ecology for the focused properties.

\begin{tabular}{|c|c|c|c|c|c|c|c|}
\hline Indicador & P1 & $\mathbf{P 2}$ & P3 & P4 & P5 & P6 & P7 \\
\hline Fisionomia e conservação dos hábitats naturais & 0,71 & 0,67 & 0,68 & 0,64 & 0,78 & 0,67 & 0,72 \\
\hline $\begin{array}{l}\text { Diversidade e condição de manejo das áreas de produção } \\
\text { agropecuária }\end{array}$ & 0,67 & 0,71 & 0,86 & 0,88 & 0,80 & 0,71 & 1,00 \\
\hline $\begin{array}{l}\text { Diversidade e condição de manejo das atividades não agrícolas } \\
\text { e confinamento animal }\end{array}$ & 0,62 & 0,62 & 0,75 & 0,86 & 1,00 & 0,90 & 0,86 \\
\hline Cumprimento com requerimento de reserva legal & 0,97 & 0,97 & 0,97 & 0,17 & 0,14 & 0,94 & 0,99 \\
\hline $\begin{array}{l}\text { Cumprimento com requerimento de proteção de áreas de } \\
\text { preservação permanente }\end{array}$ & 0,93 & 0,93 & 0,93 & 0,00 & 0,84 & 0,93 & 0,81 \\
\hline Corredores de fauna & 0,68 & 0,68 & 0,68 & 0,68 & 0,68 & 0,86 & 0,68 \\
\hline Diversidade da paisagem & 0,24 & 0,69 & 0,77 & 0,47 & 0,40 & 0,49 & 0,79 \\
\hline Diversidade produtiva & 0,02 & 0,48 & 0,54 & 0,67 & 0,44 & 0,27 & 0,74 \\
\hline Regeneração de áreas degradadas & 0,70 & 0,70 & 0,70 & 0,70 & 0,70 & 0,65 & 0,70 \\
\hline Incidência de focos de vetores de doenças endêmicas & 0,78 & 0,56 & 0,47 & 0,67 & 0,66 & 0,67 & 0,67 \\
\hline Risco de extinção de espécies ameaçadas & 0,70 & 0,70 & 0,70 & 0,70 & 0,70 & 0,70 & 0,70 \\
\hline Risco de incêndio & 1,00 & 1,00 & 1,00 & 1,00 & 0,85 & 0,85 & 1,00 \\
\hline Risco geotécnico & 0,70 & 0,70 & 0,70 & 0,70 & 0,70 & 0,70 & 0,70 \\
\hline
\end{tabular}

O índice de impacto ambiental do indicador requerimento de proteção de áreas de preservação permanente para quase todas as propriedades esteve próximo a 1,0, que é o valor máximo a ser alcançado, ou seja, um desempenho ambiental ótimo. P4 foi a exceção, pois teve o índice de impacto ambiental para esse requerimento igual a zero, o que é plenamente justificado, porque não existe dentro dessa propriedade área proteção permanente, conforme estabelece a Lei Federal $\mathbf{n}^{\circ} 4.771$, de 15 de setembro de 1965 (Código Florestal).

Para o indicador risco de extinção de espécies ameaçadas, encontrou-se o valor 0,70 no índice de impacto ambiental (igual à linha-base), pois não há espécies identificadas com risco de extinção e o Sistema apresenta a opção que atribui 0,70 (valor da linha-base) quando ocorre a inexistência do risco de extinção.

Apesar de o indicador risco geotécnico refletir os riscos de natureza física, possíveis sinistros ou perda de qualidade ambiental decorrentes das atividades agropecuárias, este não foi aplicável às propriedades avaliadas, pois elas não são afetadas por nenhum risco geotécnico.

Para melhorar ou manter seu desempenho ambiental, de acordo os resultados obtidos, para os índices de impacto ambiental dos indicadores da dimensão ecologia da paisagem, os proprietários devem atender à legislação vigente (indicadores cumprimentos com requerimento de reserva legal e cumprimento com requerimento de áreas de preservação permanente), à diversificação da paisagem (indicador diversidade da paisagem) e à diversificação da produção (indicador diversidade da produção).

Os índices de impacto ambiental da dimensão compartimentos ambientais (Tabela 2) obtidos para as todas as propriedades foram superiores à linha-base de 0,70 , ou seja, as atividades desenvolvidas nas propriedades avaliadas não comprometem a qualidade dos compartimentos ambientais.

A propriedade com menor impacto ambiental para a dimensão compartimentos ambientais foi a que possui como atividade produtiva a silvicultura de eucalipto (P6). Nela encontrou-se IIAD compartimento ambiental igual a 0,86 , pois a atividade de silvicultura de eucalipto possui tratos culturais menos intensos que outras culturas.

A maioria das propriedades analisadas obteve IIAD compartimentos ambientais próximos do valor médio de 0,82. Três propriedades apresentaram índice de impacto ambiental da dimensão compartimentos ambientais inferior à média: P4 (avicultura de corte e postura), P6 (horticultura convencional e pecuária leiteira) e P7 (horticultura convencional).Todas localizadas no município de Confresa/MT, no assentamento Xavante.

Na tabela4 constam os valores dos índices de impacto ambiental dos indicadores que compõem a subdimensão atmosfera. 
Tabela 4. Índice de impacto ambiental dos indicadores da subdimensão atmosfera para as propriedades estudadas.

Table 4. Index of environmental impact of indicators of sub-dimension atmosphere for the focused properties.

\begin{tabular}{lccccccc}
\hline Indicador & P1 & P2 & P3 & P4 & P5 & P6 & P7 \\
\hline Partículas em suspensão/fumaça & 0,77 & 0,81 & 0,77 & 1,00 & 0,77 & 0,77 & 0,77 \\
Odores & 0,77 & 0,77 & 0,77 & 1,00 & 0,77 & 0,77 & 0,77 \\
Ruído & 1,00 & 0,77 & 0,77 & 0,77 & 0,77 & 0,77 & 0,77 \\
Óxidos de carbono/hidrocarbonetos & 0,87 & 0,87 & 0,84 & 0,87 & 0,87 & 0,70 & 0,87 \\
Óxidos de enxofre & 0,87 & 0,87 & 0,84 & 0,87 & 0,87 & 0,70 & 0,87 \\
Óxidos de nitrogênio & 0,87 & 0,87 & 0,84 & 0,87 & 0,87 & 0,70 & 0,87 \\
\hline
\end{tabular}

Os indicadores partículas em suspensão/fumaça, odores, ruído, óxidos de carbono/hidrocarbonetos, óxidos de enxofre e óxidos de nitrogênio que compõem a subdimensão atmosfera, apesar de aplicáveis para o estabelecimento rural da agricultura familiar, têm pouca representatividade e importância nessas propriedades, pois não há utilização de ferramentas, maquinário ou tecnologias que gerem os aspectos mensurados por esses indicadores.

Na tabela 5são apresentados os índices de impacto ambiental da subdimensão água superficial e subterrânea para as propriedades estudadas.

Tabela 5. Índice de impacto ambiental dos indicadores dasubdimensão água superficial e subterrânea para as propriedades estudadas.

Table 5. Index of environmental impact of indicators of sub-dimension surface water and groundwater to the focused properties.

\begin{tabular}{lccccccc}
\hline Indicador & P1 & P2 & P3 & P4 & P5 & P6 & P7 \\
\hline Oxigênio dissolvido - água superficial & 0,83 & 0,92 & 0,75 & - & 0,73 & 0,74 & 0,74 \\
Coliformes fecais - água superficial & 1,00 & 1,00 & 1,00 & - & 1,00 & 1,00 & 1,00 \\
DBO5 - água superficial & 0,99 & 0,99 & 0,99 & - & 0,99 & 0,99 & 0,99 \\
pH - água superficial & 0,99 & 0,99 & 0,99 & - & 0,99 & 0,99 & 0,99 \\
Nitrato - água superficial & 1,00 & 1,00 & 1,00 & - & 1,00 & 1,00 & 1,00 \\
Fosfato - água superficial & 1,00 & 0,89 & 0,95 & - & 0,82 & 0,97 & 0,97 \\
Turbidez - água superficial & 1,00 & 0,99 & 1,00 & - & 1,00 & 0,87 & 1,00 \\
Clorofila a - água superficial & 1,00 & 1,00 & 1,00 & - & 1,00 & 1,00 & 1,00 \\
Condutividade - água superficial & 0,93 & 0,91 & 0,92 & - & 0,92 & 0,93 & 0,92 \\
Poluição visual - água superficial & 1,00 & 1,00 & 1,00 & - & 1,00 & 1,00 & 1,00 \\
Impacto potencial de pesticidas - água superficial & 0,90 & 0,65 & 0,65 & - & 0,65 & 0,98 & 0,65 \\
Coliformes fecais - água subterrânea & - & - & - & 1,00 & - & - & - \\
Nitrato - água subterrânea & - & - & - & 1,00 & - & - & - \\
Condutividade - água subterrânea & - & - & - & 0,92 & - & - & - \\
\hline
\end{tabular}

Os indicadores 1) Coliformes fecais - água subterrânea, 2) Nitrato - água subterrânea e 3) Condutividade - água subterrânea foram aplicáveis exclusivamente a P4 (avicultura de corte e postura), pois é a única que utiliza água de poço na produção, por não haver na propriedade ou nasproximidades curso d'água que permita a utilização por gravidade.

$\mathrm{Na}$ tabela 6 são apresentados os valores dos índices de impacto ambiental dos indicadores ambientais da subdimensão solo - conservação e capacidade produtiva das propriedades estudadas.

A subdimensão solo - conservação e capacidade produtiva apresentou os indicadores com os valores de pior desempenho ambiental (acidez potencial $-\mathrm{H}+\mathrm{Al}$, e volume de bases) para todas as propriedades avaliadas, fato decorrente das características do solo das regiões onde se localizam os assentamentos.

Para o indicador fósforo (P resina), a dificuldade encontrada para sua aplicação é técnica, uma vez que na região o método não é amplamente utilizado, nem em laboratórios credenciados pela Embrapa. O método mais utilizado para a determinação dos teores de fósforo é o Mehlich-1. 
Os valores elevados do índice de impacto ambiental $\mathrm{pH}$ do solo $(0,99)$ indicam que práticas corretivas foram utilizadas, da mesma forma que o manejo do solo em relação ao indicador matéria orgânica tem observado os aspectos conservacionistas do solo.

O valor médio do índice de impacto ambiental da dimensão valores socioculturais (Tabela 2) foi de 0,68 , inferior ao da linha-base $(0,70)$, indicando que essa é uma dimensão que deve receber atenção nas ações do proprietário, a fim de melhorar seu desempenho ambiental (índice de impacto ambiental da propriedade).

Na tabela 7encontram-se os valores dos índices de impacto ambiental dos indicadores da dimensão valores socioculturais.

Tabela 6. Índice de impacto ambiental dos indicadores da subdimensão solo - conservação e capacidade produtiva, para as propriedades estudadas.

Table 6. Index of environmental impact of indicators of soil sub-dimension - conservation and productive capacity for the focused properties.

\begin{tabular}{lccccccc}
\hline Indicador & P1 & P2 & P3 & P4 & P5 & P6 & P7 \\
\hline Matéria orgânica & 0,86 & 0,79 & 0,70 & 0,79 & 0,91 & 0,81 & 0,76 \\
pH do solo & 0,99 & 0,99 & 0,99 & 0,99 & 0,99 & 0,99 & 0,99 \\
P resina & - & - & - & - & - & - & - \\
K trocável & 0,77 & 0,77 & 0,71 & 0,46 & 0,80 & 0,52 & 0,71 \\
Mg trocável & 0,89 & 0,77 & 0,76 & 0,96 & 0,99 & 0,67 & 0,75 \\
H+Al & 0,42 & 0,45 & 0,44 & 0,72 & 0,48 & 0,51 & 0,58 \\
Soma de bases & 0,78 & 0,87 & 0,72 & 0,56 & 0,87 & 0,48 & 0,78 \\
CTC & 0,96 & 0,97 & 0,95 & 0,86 & 0,97 & 0,91 & 0,94 \\
Volume de bases & 0,40 & 0,48 & 0,39 & 0,49 & 0,50 & 0,33 & 0,49 \\
Erosão & 0,75 & 0,68 & 0,75 & 0,75 & 0,63 & 0,60 & 0,60 \\
\hline
\end{tabular}

Tabela 7. Índice de impacto ambiental dos indicadores da dimensão valores socioculturais em assentamentos da reforma agrária.

Table 7. Index of environmental impact of indicators of social-cultural values in agrarian reform settlements.

\begin{tabular}{lccccccc}
\hline Indicador & P1 & P2 & P3 & P4 & P5 & P6 & P7 \\
\hline Acesso à educação & 0,64 & 0,76 & 0,72 & 0,73 & 0,74 & 0,74 & 0,74 \\
Acesso a serviços básicos & 0,76 & 0,86 & 0,76 & 0,54 & 0,65 & 0,71 & 0,65 \\
Padrão de consumo & 0,79 & 0,83 & 0,73 & 0,61 & 0,82 & 0,85 & 0,73 \\
Acesso a esporte e lazer & 1,00 & 1,00 & 1,00 & 1,00 & 0,70 & 1,00 & 1,00 \\
Conservação do patrimônio & - & - & - & - & - & - & - \\
histórico/artístico/arqueológico/espeleológico & - & - & - & & - & - \\
Qualidade do emprego & 0,40 & 0,25 & 0,40 & 0,30 & 0,60 & 0,50 & 0,50 \\
Segurança e saúde ocupacional & 0,58 & 0,15 & 0,53 & 0,58 & 0,58 & 0,72 & 0,15 \\
Oportunidade de emprego local qualificado & 0,71 & 0,71 & 0,71 & 0,71 & 0,71 & 0,71 & 0,71 \\
\hline
\end{tabular}

Somente a propriedade P1, que se dedica à silvicultura de eucalipto, e a propriedade P6, que pratica a horticultura convencional e pecuária leiteira, obtiveram valores de 0,70 e 0,75 , respectivamente. Mesmo estando acima da linha-base $(0,70)$, essas duas propriedades tiveram valores de índice de impacto ambiental do indicador qualidade do emprego inferior a 0,50,motivo pelo qual esse aspecto é merecedor de atenção especial.

As propriedades P2 (horticultura convencional), P4 (avicultura de corte e postura) e P7 (horticultura convencional) apresentaram desempenho ambiental semelhante, com valores de índice de impacto ambiental da dimensão valores socioculturais de 0,65, 0,64 e 0,64, respectivamente.

$\mathrm{O}$ indicador qualidade do emprego, quanto ao aspecto jornada de trabalho, apresentou um obstáculo, já que os produtores não souberam especificar a duração das horas trabalhadas semanalmente. Devido ao tipo de atividade desenvolvida nas propriedades, não há feriados e, normalmente, é necessário trabalharem horários e dias não previstos. 
A definição do período da jornada de trabalho é muito complexa e se faz por aproximação. O ritmo do trabalho depende das características das atividades desenvolvidas nas propriedades e há exigência de dedicação integral, o que não permite uma jornada de trabalho fixa. Portanto, o produtor assentado da reforma agrária obedece à demanda dos serviços da propriedade.

Os valores baixos para índice de impacto ambiental do indicador segurança e saúde ocupacional devem-se aos costumes dos produtores de não utilização de equipamentos de proteção individual (EPI).

$\mathrm{O}$ indicador conservação do patrimônio histórico/artístico/arqueológico/espeleológico não é aplicável às propriedades avaliadas, pois não há patrimônio dessa natureza nesses estabelecimentos.

$\mathrm{O}$ valor médio do índice de impacto ambiental da dimensão valores econômicos obtidos(Tabela 2) foi de 0,78 ,superior ao da linha-base, que é de 0,70 , e observou-se que todas as propriedades apresentaram um índice de impacto ambiental da dimensão valores econômicos superior ao da linha-base. $\mathrm{O}$ menor valor foi obtido pelas atividades silvicultura de eucalipto (P1) e horticultura convencional (P3 e P7).

Encontram-se na tabela 8 os valores dos índices de impacto ambiental da dimensão valores econômicos para as propriedades estudadas.

Tabela 8. Índice de impacto ambiental da dimensão valores econômicos em assentamentos da reforma agrária.

Table 8. Index of environmental impact of the economic dimension values on agrarian reform settlements.

\begin{tabular}{lccccccc}
\hline Indicador & P1 & P2 & P3 & P4 & P5 & P6 & P7 \\
\hline Renda líquida do estabelecimento & 0,34 & 0,94 & 0,94 & 0,96 & 0,74 & 0,97 & 0,66 \\
Diversidade das fontes de renda & 0,69 & 0,72 & 0,69 & 0,89 & 1,00 & 0,69 & 0,69 \\
Distribuição da renda & 0,70 & 0,70 & 0,70 & 0,70 & 0,70 & 0,70 & 0,70 \\
Nível de endividamento & 0,70 & 0,67 & 0,70 & 0,77 & 0,70 & 0,87 & 0,37 \\
Valor da propriedade & 0,91 & 0,79 & 0,61 & 1,00 & 1,00 & 1,00 & 0,96 \\
Qualidade da moradia & 0,95 & 0,95 & 0,65 & 0,65 & 0,95 & 0,65 & 0,95 \\
\hline
\end{tabular}

As propriedades localizadas no município de Confresa/MT, no assentamento Xavante, foram as que apresentram melhor desempenho no IIADvalores econômicos (P4, P5 e P6), com exceçãoda P7 (horticultura convencional), que teve índice de 0,72 , valor igual ao obtido por duas das três propriedades de Campo Verde/MT, assentamento Santo Antônio da Fartura (P1 e P3).

A propriedade P1 (silvicultura de eucalipto) obteve índice de impacto ambiental da dimensão valores econômicos influenciado negativamente pelo indicador renda líquida do estabelecimento, pois é característico da silvicultura o rendimento a médio e longo prazo.

Com relação ao indicador valor da propriedade, o produtor não possui a expectativa do valor real (ou venal) do imóvel. O que se tem é o valor estimado, que seria pago na ilegalidade (não há titulação e escrituração imobiliária nesses assentamentos) e abaixo do valor real de mercado. Portanto, a maior dificuldade nessa situação é estabelecer o módulo da alteração do valor da terra. Mesmo que isso não seja um obstáculo à aplicação do indicador, deve-se ter atenção com ele no momento da entrevista.

A média do índice de impacto ambiental da dimensão gestão e administração das propriedades avaliadas foi 0,50 , abaixo do valor da linha-base que é de 0,70 , influenciada principalmente pelo indicador relacionamento institucional, que apresentou os menores valores do índice de impacto de indicador dessa dimensão.

A tabela 9 contém os valores dos índices de impacto ambiental dos indicadores que compõem a dimensão gestão e administração das propriedades estudadas.

Todos os indicadores formadores da dimensão gestão e administração puderam ser aplicados sem dificuldades ou limitações.

Observou-se que as propriedades localizadas no município de Campo Verde/MT, assentamento Santo Antônio da Fartura, apresentaram os piores resultados para o IIAD gestão e administração. A propriedade $\mathrm{P} 3$, dedicada à horticultura convencional, foi a que apresentou o índice mais baixo $(0,17)$ entre os índices de impacto ambiental dos indicadores que compõem a referida dimensão.

$\mathrm{O}$ indicador ambiental relacionamento institucional foi o que mais contribuiu para o baixo índice de impacto ambiental da dimensão gestão e administração, pois os produtores afirmaram que não há promoção da assistência técnica. 
Tabela 9. Valores do índice de impacto ambiental dos indicadores da dimensão gestão e administração em assentamentos da reforma agrária.

Table 9. Index values of environmental impact indicators for management and administration in agrarian reform settlements.

\begin{tabular}{lccccccc}
\hline Indicadores & P1 & P2 & P3 & P4 & P5 & P6 & P7 \\
\hline Dedicação e perfil do responsável & 0,50 & 0,50 & 0,50 & 0,83 & 0,50 & 0,67 & 0,67 \\
Condição de comercialização & 0,25 & 0,25 & 0,38 & 0,63 & 0,63 & 0,63 & 0,63 \\
Reciclagem de resíduos & 0,40 & 0,40 & 0,40 & 0,60 & 0,60 & 0,80 & 0,40 \\
Gestão de insumos químicos & 0,60 & 0,60 & 0,40 & 0,60 & 0,60 & 0,80 & 0,40 \\
Relacionamento institucional & 0,33 & 0,50 & 0,17 & 0,33 & 0,33 & 0,33 & 0,33 \\
\hline
\end{tabular}

\section{CONCLUSÕES}

- Os índices de impacto ambiental das sete propriedades avaliadas demonstram que não há comprometimento da qualidade ambiental por parte de nenhuma das atividades desenvolvidas nos assentamentos de reforma agrária estudados.

- No nível das dimensões, com exceção da dimensão gestão e administração, as práticas agrícolas são compatíveis com o padrão de desenvolvimento ambientalmente sustentável.

- A dimensão gestão e administração e os indicadores que a compõem revelaram-se pontos críticos no desempenho ambiental das atividades desenvolvidas nas propriedades de assentamento rural.

- A utilização do indicador fósforo (P) pelo método de determinação resina é limitado por dificuldades de acesso aos laboratórios acreditados que utilizam esse método.

- A existência de uma única linha de referência limita a interpretação do impacto ambiental causado.

\section{REFERÊNCIAS}

ALMEIDA, J. R. de; SOARES, P. S. M. (eds.). Análisis y evaluaciones de impactos ambientales. Rio de Janeiro: CETEM/MCT, 2008.

AMERICAN PUBLIC HEALTH ASSOCIATION. Standard Methods for the examination of water and wastewater.16th ed. Washington: APHA, 1985.

BRAGA, B.; HESPANHOL, I.; CONEJO, J. G. L.; MIERZWA, J. C.; BARROS, M. T. L.; SPENCER, M.; PORTO, M.; NUCCI, N.; JULIANO, N.; EIGER, S. Introdução à Engenharia Ambiental. 2 reimp. São Paulo: Prentice Hall, 2002. 305 p.

CLAESSEN, M. E. C. (org.). Manual de métodos de análise de solo. 2. ed. rev. e atual. Rio de Janeiro: EMBRAPA-CNPS, 1997, 212 p.

FILIZOLA, H. F.; GOMES. M. A. F.; SOUZA. M. D. Manual de procedimentos de coleta de amostras em áreas agrícolas para análise da qualidade ambiental: solo, água e sedimentos. Jaguariúna: EMBRAPA Meio Ambiente, 2006, 169 p.

GUERRA, R. M. N. Discutindo a sustentabilidade nos PDS (Projetos de Desenvolvimento Sustentável): um diagnóstico do PDS São Salvador. In: FERREIRA NETO, J. A., DOULA, S. M. (orgs.) Assentamentos rurais e meio ambiente no Brasil: atores sociais, processos produtivos e legislação. Viçosa: UFV, DER, 2006.

PEREIRA, J. A. A.; BORÉM, R. A. T.; SANT`ANA, C.M.Análise e avaliação de impactos ambientais. Lavras: UFLA/FAEPE, 2001, $147 \mathrm{p}$.

RAMOS FILHO, L. O.; RODRIGUES, I.; FRIGHETTO, R. T. S.; RODRIGUES, G. S.; CAMPANHOLA, C.; BROMBAL, J. C. Aplicação do Sistema "Apoia-NovoRural" para avaliação do desempenho ambiental do agroturismo. Cadernos de Ciência \& Tecnologia, Brasília, v. 21, n. 3, p. 409 - 423, 2004. 
RODRIGUES, G. S.; CAMPANHOLA, C. Sistema integrado de avaliação de impacto ambiental aplicado a atividades do Novo Rural. Pesq. agropec. bras., Apr. 2003, v.38, n.4, p.445 - 451.

RODRIGUES, G. S.; CAMPANHOLA, C.; VALARINI, P. J.;QUEIROZ, J. F. de; FRIGHETTO, R. T. S.; RAMOS FILHO, L. O.;RODRIGUES, I.; BROMBAL, J. C.; TOLEDO, L. G. de. Avaliação de impacto ambiental de atividades produtivas em estabelecimentos familiares do Novo Rural. Boletim de Pesquisa e Desenvolvimento, nº17. Jaguariúna: Embrapa Meio Ambiente, 2003. 46p.

RODRIGUES, G. S.; VALARINI, P. J.; FRIGHETTO, R. T. S.; CAMPANHOLA, C.; RAMOS FILHO, L. O.; RODRIGUES, I. Avaliação de impacto ambiental de alternativas de manejo na horticultura. Revista Científica Rural, v. 11, p. 1 - 7, 2006.

RODRIGUES, G. S.; RODRIGUES, I. Avaliação de impactos ambientais na agropecuária. In: GLEBER, L., PALHARES, J. C. P. Gestão ambiental na agropecuária. Informação Tecnológica. Brasília: Embrapa, 2006.

RODRIGUES, G. S., MOREIRA, A. (coords.). Manual de evaluación de impacto ambiental de actividades rurales/IICA. Montevideo: MGAP, BM, GEF, Proyecto Producción Responsable, IICA, PROCISUR, EMBRAPA, 2007.

SÁNCHEZ, L. E. Avaliação de impacto ambiental: conceitos e métodos. São Paulo: Oficina de Textos, 2006. 495p.

SANTOS, R. F. dos. Planejamento ambiental: teoria e prática. São Paulo: Oficina de Textos, 2004, $184 \mathrm{p}$. 
